\title{
PENGARUH TINGKAT PENGETAHUAN DAN SIKAP TERHADAP PENGGUNAAN ANTIBIOTIK DI APOTEK KIMIA FARMA 396 TUMINTING KOTA MANADO
}

\section{THE INFLUENCE OF KNOWLEDGE LEVELS AND ATTITUDES TOWARDS ANTIBIOTICS AT KIMIA FARMA PHARMACY 396 TUMINTING MANADO CITY}

\author{
Inchristy Victoria Kondoj ${ }^{1)}$, Widya Astuty Lolo ${ }^{1)}$, Imam Jayanto ${ }^{1)}$ \\ 1) Program Studi Farmasi FMIPA UNSRAT Manado, 95115
}

\begin{abstract}
Irrational use of antibiotics occurs because of a lack of public knowledge about the use of antibiotics that a good and right. Good knowledge will change attitudes so that the actions taken become directed. This study aims to determine the effect of the level of knowledge and attitudes of the community towards the use of antibiotics at Kimia Farma Pharmacy 396 Tuminting, Manado city. This research is a descriptive study and data collection tool used is a questionnaire about antibiotic knowledge and attitudes towards antibiotic use to 290 respondents. Based on the research results obtained, it is known that the level of public knowledge about antibiotics is still classified as a poor with a percentage of $69 \%$ while public attitudes towards the use of antibiotics are quite sufficient with a percentage of $45 \%$ and there is an influence between the level of knowledge and attitudes towards antibiotic use with a significant value of 0,000.
\end{abstract}

Key words : Antibiotics, Level of Knowledge, Attitude.

\begin{abstract}
ABSTRAK
Penggunaan antibiotik yang tidak rasional terjadi karena kurangnya pengetahuan masyarakat tentang penggunaan antibiotik yang baik dan benar. Pengetahuan yang baik akan merubah sikap sehingga tindakan yang diambil menjadi terarah. Penelitian ini bertujuan untuk mengetahui pengaruh tingkat pengetahuan dan sikap masyarakat terhadap penggunaan antibiotik di Apotek Kimia Farma 396 Tuminting, kota Manado. Penelitian ini merupakan penelitian deskriptif dan alat pengumpulan data yang digunakan yaitu kuesioner tentang pengetahuan antibiotik dan sikap terhadap penggunaan antibiotik kepada 290 responden. Berdasarkan hasil penelitian yang diperoleh, diketahui bahwa tingkat pengetahuan masyarakat tentang antibiotik masih tergolong kurang dengan persentase $69 \%$ sementara sikap masyarakat terhadap penggunaan antibiotik tergolong cukup dengan persentase $45 \%$ dan terdapat pengaruh antara tingkat pengetahuan dan sikap terhadap penggunaan antibiotik dengan nilai signifikan sebesar 0,000.
\end{abstract}

Kata kunci : Antibiotik, Tingkat Pengetahuan, Sikap. 


\section{PENDAHULUAN}

Penggunaan antibiotik yang tidak rasional menyebabkan masalah resistensi, sehingga bakteri tidak peka terhadap antibiotik. Resistensi silang terjadi pada antibiotik yang memiliki cara kerja yang hampir sama seperti eritromisin dan linkomisin (Tripathi, 2008). Antibiotik merupakan obat yang digunakan untuk mencegah atau mengobati suatu infeksi bakteri. Antibiotik banyak diresepkan pada pasien, namun penggunaannya sering kali tidak tepat. Salah satu penelitian menunjukkan bahwa masih banyak masyarakat yang mengggunakan amoksisilin untuk pengobatan sendiri tanpa mengetahui cara pemakaian dan dampaknya bagi kesehatan (Parumpu, 2016). Hal ini terjadi karena faktor kurangnya informasi yang akurat sehingga dapat mengakibatkan tingginya tingkat konsumsi yang tidak tepat (Baltazar et al., 2009).

Penelitian yang lain menunjukkan bahwa terdapat $77 \%$ antibiotik dibeli tanpa resep dokter. Antibiotik tersebut dibeli untuk mengobati gejala flu, demam, batuk, sakit tenggorokan, sakit kepala, dan gejala sakit ringan lainnya (Widayati et al., 2012). Penelitian yang berhubungan dengan tingkat pengetahuan tentang antibiotik memberikan hasil sebanyak $21 \%$ responden tidak mengenal antibiotik dan $12 \%$ memiliki tingkat pengetahuan yang rendah (Pratiwi et al., 2013). Penggunaan antibiotik memerlukan pengetahuan dan sikap tentang cara pemakaian yang tepat. Pengetahuan merupakan aspek penting dalam proses terbentuknya tindakan yang nyata. Pengetahuan yang baik akan merubah sikap positif sehingga tindakan yang diambil menjadi terarah (Haryanto et al., 2016). Penelitian yang dilakukan di Kabupaten Lampung Timur memberikan hasil sebesar $65 \%$ tingkat pengetahuan masyarakat terhadap antibiotik baik dan sebesar $60 \%$ sikap positif terhadap penggunaan antibiotik (Pratiwi, 2018). Sedangkan penelitian yang dilakukan di Kabupaten Aceh Besar diperoleh hasil bahwa tingkat pengetahuan masyarakat terhadap antibiotik masih kurang (54\%) dan sikap terhadap penggunaan antibiotik juga masih kurang (57\%) (Rahmawati, 2017). Inilah yang menyebabkan pentingnya pengetahuan masyarakat tentang penggunaan antibiotik. Berdasarkan latar belakang tersebut, maka dilakukan penelitian tentang Pengaruh Tingkat Pengetahuan dan Sikap Terhadap Penggunaan Antibiotik di Apotek Kimia Farma 396 Tuminting kota Manado.

\section{METODOLOGI PENELITIAN}

\section{Waktu dan Tempat Penelitian}

Penelitian ini dilaksanakan pada bulan Desember 2019 - Juni 2020 di Apotek Kimia Farma 396 Tuminting kota Manado.

\section{Jenis Penelitian}

Penelitian ini merupakan penelitian deskriptif. Hal ini karena dalam penelitian ini hanya menjelaskan bagaimana tingkat pengetahuan penggunaan antibiotik dan sikap terhadap penggunaan antibiotik pada pengunjung Apotek Kimia Farma 396 Tuminting kota Manado.

\section{Alat dan Bahan \\ Alat}

Alat yang digunakan dalam penelitian ini yaitu: alat tulis, lembar kuesioner, dan kamera untuk dokumentasi.

\section{Bahan}

Bahan yang digunakan dalam penelitian terdiri dari:

1. Data Primer

Data primer yang digunakan dalam penelitian ini didapat dari kuesioner yang diisi oleh responden, juga wawancara yang dilakukan kepada Apoteker Pengelola Apotek Kimia Farma 396 Tuminting kota Manado.

2. Data Sekunder

Data sekunder yang digunakan dalam penelitian ini adalah studi bahan kepustakaan berupa jurnal dan artikel penelitian untuk mendukung data primer. 


\section{Populasi Penelitian}

Populasi adalah suatu objek yang mempunyai karakteristik tertentu oleh peneliti untuk dipelajari dan kemudian ditarik kesimpulannya. Populasi dalam penelitian ini yaitu pengunjung pada Apotek Kimia Farma 396 Tuminting kota Manado. Metode pengumpulan data yang digunakan dalam penelitian ini menggunakan kuesioner yang dibagikan kepada responden.

\section{Sampel Penelitian}

Pemilihan sampel menggunakan teknik accidental sampling. Dalam hal ini objek penelitian dianggap paling tahu tentang apa yang kita harapkan sehingga peneliti mudah untuk mengamati objek yang diteliti. Sampel yang digunakan harus memenuhi kriteria inklusi dan eksklusi.

1. Kriteria inklusi :

a. Pasien yang berusia $\geq 17$ tahun (Depkes, 2009).

b. Pasien yang pernah atau sedang menggunakan antibiotik.

2. Kriteria eksklusi :

a. Pasien tidak mengetahui tentang antibiotik.

b. Pasien membeli antibiotik tetapi digunakan oleh orang lain.

Sampel yang digunakan dalam penelitian ini dihitung menggunakan rumus Slovin, yaitu:

$$
\mathrm{n}=\frac{N}{1+N(e)^{2}}
$$

Keterangan :

$\mathrm{n}=$ Ukuran sampel atau jumlah responden

$\mathrm{N}=$ Ukuran populasi

$\mathrm{e}=$ Persentase kelonggaran ketelitian pengambilan sampel yang masih bisa ditolerir $(0,05)$.

Berdasarkan perhitungan tersebut maka jumlah sampel yang digunakan dalam penelitian ini sebanyak 290 responden.

\section{Hipotesis Penelitian}

Hipotesis dalam penelitian ini yaitu :

$\mathrm{H}_{0}$ : Tidak ada pengaruh antara tingkat pengetahuan dan sikap terhadap penggunaan antibiotik pada masyarakat pengunjung Apotek Kimia Farma 396 Tuminting kota Manado.

$\mathrm{H}_{1}$ : Ada pengaruh antara tingkat pengetahuan dan sikap terhadap penggunaan antibiotik pada masyarakat pengunjung Apotek Kimia Farma 396 Tuminting kota Manado.

\section{Analisis Data}

Analisis data yaitu pengelompokkan data berdasarkan variabel dan jenis responden. Metode analisis data yang digunakan dalam penelitian ini adalah metode analisis statistik deskriptif. Analisis data untuk pengetahuan tentang antibiotik menggunakan kuesioner tertutup dengan kategori benar dan salah. Sedangkan kategori jawaban untuk kuesioner tentang sikap menggunakan skala likert dari skala 1 sampai 4 pada tiap pernyataan yang berbeda. Lalu dihitung persentase pernyataan yang dijawab. Selanjutnya dihitung dengan rumus persen untuk pernyataan yang dijawab benar dan dikategorikan. Berdasarkan nilai persentase tersebut, didapatkan nilai pengetahuan berupa baik ( $\geq 75 \%$ ), cukup (56\%-74\%), dan kurang $(\leq 55 \%) \quad$ (Arikunto, 2006). Hasil yang diperoleh lalu dikategorikan menjadi baik, cukup, dan kurang sesuai dengan kategori pada tingkat pengetahuan. Selanjutnya dihitung persentase responden tiap kategori.

Uji normalitas data digunakan untuk mengetahui data terdistribusi normal atau tidak. Hal ini menggunakan uji KolmogrovSmirnov, dimana sampel terdistribusi normal apabila nilai asymptotic sig $>0,05$. Jika hasil terdistribusi normal maka analisa statistik memakai statistik parametrik. Dalam penelitian ini statistik parametrik yang digunakan yaitu uji Paired Sample T-test. Paired Sample T-test digunakan untuk menguji perbedaan dua sampel yang berpasangan. Jika dari hasil pengujian nilai signifikan > 0,05 maka $\mathrm{H}_{0}$ diterima dan $\mathrm{H}_{1}$ ditolak. Jika nilai signifikan $<0,05$ maka $\mathrm{H}_{0}$ ditolak dan $\mathrm{H}_{1}$ diterima (Santoso, 2016). Hipotesis dalam penelitiannya ini berupa $\mathrm{H}_{0}$ yakni tidak ada pengaruh antara tingkat pengetahuan dan sikap terhadap penggunaan 
antibiotik pada masyarakat pengunjung Apotek Kimia Farma 396 Tuminting kota Manado sedangkan $\mathrm{H}_{1}$ yakni ada pengaruh antara tingkat pengetahuan dan sikap terhadap penggunaan antibiotik pada masyarakat pengunjung Apotek Kimia Farma 396 Tuminting kota Manado.

\section{HASIL DAN PEMBAHASAN}

Karakteristik Responden

Tabel 1. Karakteristik Responden

\begin{tabular}{lll}
\hline \multirow{2}{*}{ Karakteristik } & \multicolumn{2}{c}{ Total } \\
\cline { 2 - 3 } & $\mathbf{n}$ & $(\%)$ \\
(Jumlah) & \\
\hline
\end{tabular}

\begin{tabular}{lll}
\hline Jenis Kelamin & & \\
Pria & 110 & 38 \\
Wanita & 180 & 62 \\
\hline
\end{tabular}

\begin{tabular}{lcc}
\hline Usia $\quad$ (Depkes, & & \\
2009) & & \\
$(17-25$ tahun) & 14 & 4,8 \\
$(26-35$ tahun) & 38 & 13,1 \\
$(36-45$ tahun) & 33 & 11,4 \\
(46 - 55 tahun) & 78 & 26,9 \\
(56 - 65 tahun) & 71 & 24,5 \\
(>65 tahun) & 56 & 19,3 \\
\hline
\end{tabular}

\section{Pendidikan}

Terakhir

\begin{tabular}{lcc} 
SD & 52 & 17,9 \\
SMP & 59 & 20,3 \\
SMA & 117 & 40,3 \\
Diploma/Sarjana & 61 & 21 \\
Lainnya & 1 & 0,3 \\
\hline
\end{tabular}

\begin{tabular}{lcc}
\hline Jenis Pekerjaan & & \\
Tidak bekerja/MRT & 136 & 46,8 \\
Wiraswasta & 46 & 15,8 \\
PNS & 20 & 6,8 \\
Buruh/Karyawan & 39 & 13,4 \\
Petani & 4 & 1,3 \\
Lainnya & 45 & 15,5 \\
\hline \multicolumn{1}{c}{ Karakteristik } & responden & dalam
\end{tabular}

penelitian ini dibagi berdasarkan jenis kelamin, usia, pendidikan terakhir, dan pekerjaan. Responden dalam penelitian yaitu pengunjung Apotek Kimia Farma 396 Tuminting kota Manado. Berdasarkan Tabel 1 dapat diketahui bahwa responden pria sebanyak $38 \%$ dan responden wanita sebanyak 62\%. Pada karakteristik usia, diketahui bahwa jumlah responden dengan rentang usia paling tinggi yaitu $46-55$ tahun dan paling rendah yaitu $17-25$ tahun. Usia merupakan salah satu faktor yang dapat mempengaruhi pengetahuan. Hal ini dikarenakan usia mempengaruhi daya tangkap dan pola pikir seseorang. Bertambahnya usia akan semakin berkembang pola pikir dan daya tangkap seseorang sehingga pengetahuan yang diperoleh semakin banyak (Fitriani et al., 2015). Hasil yang diperoleh berdasarkan karakteristik pendidikan, diketahui bahwa responden dengan pendidikan terakhir paling banyak yaitu SMA (40,3\%). Semakin tinggi tingkat pendidikan seseorang akan semakin mudah menerima informasi sehingga semakin banyak pula pengalaman yang dimiliki (Carter, 2011). Berdasarkan karakteristik pekerjaan, jumlah responden paling banyak yaitu tidak bekerja/MRT (46,8\%). Pekerjaan seseorang akan berpengaruh terhadap pengetahuan dan pengalaman seseorang. Hal ini disebabkan saat orang bekerja akan menggunakan otak dan kemampuan tubuh sehingga bisa menyimpan atau ada peningkatan daya ingat karena sering melakukannya (Pangesti, 2012).

\section{Tingkat Pengetahuan Responden Terhadap Penggunaan Antibiotik}

Penilaian tingkat pengetahuan masyarakat terhadap penggunaan antibiotik menggunakan kuesioner yang terdiri dari 10 item pernyataan dengan pilihan jawaban benar atau salah. Pemberian skor pada kuesioner ini yaitu 1 dan 0 yang berbeda pada tiap item. Tabel 2 menunjukkan distribusi jawaban responden pengunjung Apotek Kimia Farma 396 Tuminting kota Manado terhadap 10 item pernyataan tentang pengetahuan antibiotik. 
Tabel 2. Pernyataan Tingkat Pengetahuan Antibiotik ( $\mathrm{n}=290)$

\begin{tabular}{|c|c|c|c|}
\hline No & Pernyataan & $\begin{array}{c}\text { Jawaban Benar } \\
(\%)\end{array}$ & $\begin{array}{c}\text { Jawaban } \\
\text { Salah }(\%)\end{array}$ \\
\hline 1 & Antibiotik adalah obat untuk infeksi bakteri & 62 & 38 \\
\hline 2 & $\begin{array}{l}\text { Jumlah antibiotik yang diberikan oleh dokter } \\
\text { boleh dikurangi jika kondisi sudah membaik }\end{array}$ & 33,1 & 66,9 \\
\hline 3 & Semua antibiotik diminum 3 kali sehari & 31,7 & 68,3 \\
\hline 4 & $\begin{array}{l}\text { Penggunaan antibiotik boleh dihentikan } \\
\text { ketika gejala sudah hilang }\end{array}$ & 28,2 & 71,8 \\
\hline 5 & $\begin{array}{l}\text { Efek samping yang sering muncul saat } \\
\text { menggunakan antibiotik adalah alergi, mual, } \\
\text { muntah, dan diare }\end{array}$ & 34 & 66 \\
\hline 6 & Antibiotik harus dibeli dengan resep dokter & 56,9 & 43,1 \\
\hline 7 & Amoksisilin adalah antibiotik & 72 & 28 \\
\hline 8 & $\begin{array}{l}\text { Antibiotik dapat digunakan untuk mengobati } \\
\text { flu dan demam }\end{array}$ & 43,1 & 56,9 \\
\hline 9 & $\begin{array}{l}\text { Antibiotik boleh disimpan dan digunakan } \\
\text { kembali saat sakit kambuh }\end{array}$ & 27,9 & 72,1 \\
\hline 10 & $\begin{array}{l}\text { Penggunaan antibiotik yang tidak sesuai } \\
\text { dapat menyebabkan kebalnya bakteri } \\
\text { terhadap antibakteri sehingga pasien menjadi } \\
\text { tidak sembuh }\end{array}$ & 43,8 & 56,2 \\
\hline
\end{tabular}

Setelah kuesioner dianalisa, untuk mengetahui tingkat pengetahuan masyarakat tentang antibiotik maka perlu dihitung untuk mengetahui skor tiap responden agar dapat dikategorikan menjadi BAIK, CUKUP, atau KURANG. Selanjutnya dihitung persentasi responden tiap kategori yang dapat dilihat pada Gambar 1.

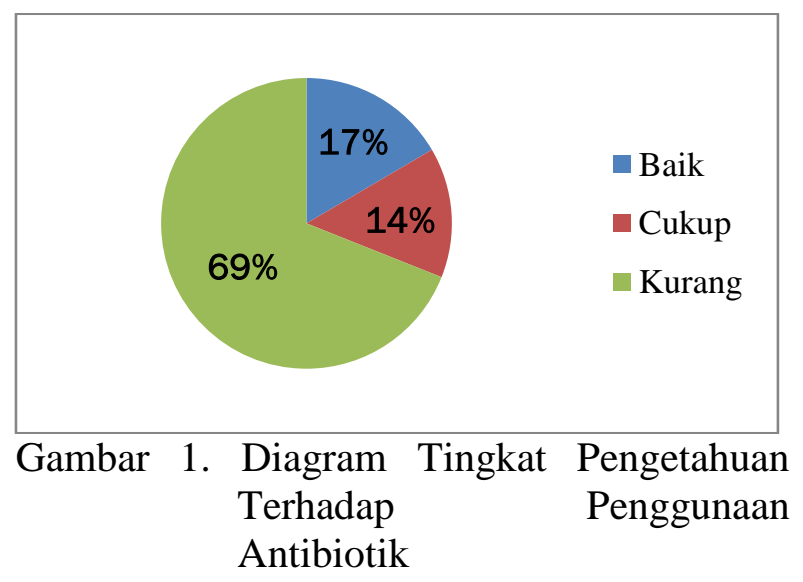

Berdasarkan Gambar 1, dari 10 item pernyataan tentang pengetahuan antibiotik yang dijawab oleh responden, diketahui bahwa kategori pengetahuan masyarakat tentang antibiotik yaitu baik $17 \%$, cukup
14\%, dan kurang 69\%. Hal ini menunjukkan bahwa mayoritas responden pengunjung Apotek Kimia Farma 396 Tuminting kota Manado memiliki tingkat pengetahuan antibiotik yang masih tergolong kurang. Adapun beberapa faktor yang dapat mempengaruhi pengetahuan masyarakat tentang penggunaan antibiotik yaitu pengalaman, tingkat pendidikan, keyakinan, fasilitas, penghasilan dan sosial budaya (Notoatmodjo, 2003).

\section{Sikap Responden Terhadap Penggunaan Antibiotik}

Penelitian tentang sikap responden terhadap penggunaan antibiotik menggunakan kuesioner yang terdiri dari 11 item pernyataan dengan pilihan jawaban selalu, sering, kadang-kadang, dan tidak pernah. Setiap item pernyataan diberi skor 1 sampai 4 dan pemberian skor pada item pernyataan berbeda-beda tergantung jenis pernyataan dalam kuesioner. Tabel 3 menunjukkan distribusi jawaban tentang pernyataan sikap terhadap penggunaan antibiotik. 
Tabel 3. Pernyataan Sikap Terhadap Penggunaan Antibiotik ( $\mathrm{n}=290)$

\begin{tabular}{|c|c|c|c|c|c|}
\hline No & Pernyataan & $\begin{array}{c}\text { Selalu } \\
(\%)\end{array}$ & $\begin{array}{c}\text { Sering } \\
(\%)\end{array}$ & $\begin{array}{l}\text { Kadang- } \\
\text { kadang } \\
(\%)\end{array}$ & $\begin{array}{c}\text { Tidak } \\
\text { Pernah } \\
(\%)\end{array}$ \\
\hline 1 & $\begin{array}{l}\text { Saya menggunakan antibiotik ketika } \\
\text { terkena infeksi bakteri }\end{array}$ & 4,4 & 15,5 & 43,4 & 36,5 \\
\hline 2 & $\begin{array}{l}\text { Saya membeli antibiotik dengan resep } \\
\text { dokter }\end{array}$ & 20 & 12,7 & 40,6 & 26,5 \\
\hline 3 & $\begin{array}{l}\text { Saya menggunakan antibiotik atas saran } \\
\text { dari keluarga atau teman tanpa periksa } \\
\text { ke dokter }\end{array}$ & 21 & 27,9 & 11,7 & 39,3 \\
\hline 4 & $\begin{array}{l}\text { Saya mengurangi jumlah antibiotik yang } \\
\text { diberikan dokter jika merasa membaik }\end{array}$ & 6,2 & 30,6 & 21 & 42 \\
\hline 5 & $\begin{array}{l}\text { Jika dokter menuliskan antibiotik } \\
\text { diminum } 3 \times 1 \text {, maka saya meminumnya } \\
\text { pagi, siang, dan malam (tanpa } \\
\text { memperhatikan jam) }\end{array}$ & 33,4 & 46,8 & 12 & 42 \\
\hline 6 & $\begin{array}{l}\text { Saya tetap meminum antibiotik sesuai } \\
\text { aturan dari dokter meskipun sudah } \\
\text { merasa baik }\end{array}$ & 14,1 & 21,7 & 17,5 & 46,5 \\
\hline 7 & $\begin{array}{l}\text { Saya menyimpan antibiotik dan } \\
\text { menggunakannya kembali saat sakit } \\
\text { kambuh }\end{array}$ & 25,5 & 25,8 & 23,1 & 25,5 \\
\hline 8 & $\begin{array}{l}\text { Saya segera mengganti jenis antibiotik } \\
\text { yang saya gunakan apabila gejala yang } \\
\text { saya alami tidak segera membaik }\end{array}$ & 6,8 & 20,6 & 20 & 52,4 \\
\hline 9 & $\begin{array}{l}\text { Saya berbagi antibiotik jika kerabat saya } \\
\text { sedang sakit }\end{array}$ & 17,5 & 20,6 & 27,5 & 34,1 \\
\hline 10 & $\begin{array}{l}\text { Jika timbul efek samping ketika } \\
\text { menggunakan antibiotik, maka saya } \\
\text { langsung berkonsultasi dengan dokter } \\
\text { atau apoteker }\end{array}$ & 38,9 & 28,6 & 21,7 & 10,6 \\
\hline 11 & $\begin{array}{l}\text { Saya minum antibiotik (sebelum atau } \\
\text { sesudah makan) disesuaikan dengan } \\
\text { anjuran dokter }\end{array}$ & 43,4 & 34,4 & 16,8 & 5,1 \\
\hline
\end{tabular}

Seperti halnya analisa yang dilakukan pada kuesioner tingkat pengetahuan antibiotik, setelah kuesioner tentang sikap terhadap penggunaan antibiotik dianalisa, untuk mengetahui kategori jawaban responden maka perlu dihitung persentase pernyataan yang dijawab benar oleh responden agar dapat dikategorikan menjadi
BAIK, CUKUP, atau KURANG. Selanjutnya dihitung persentasi jumlah responden untuk kategori baik, cukup, dan kurang yang dapat dilihat pada Gambar 2. 


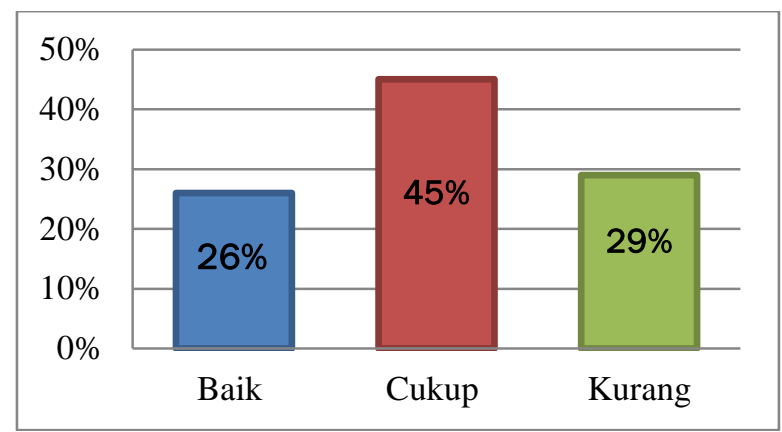

Gambar 2. Pernyataan Sikap Terhadap Penggunaan Antibiotik

Berdasarkan Gambar 2, diketahui bahwa tingkat perilaku/sikap terhadap penggunaan antibiotik pada kategori baik sebesar 26\%, cukup $45 \%$, dan kurang $29 \%$. Hal ini menunjukkan bahwa mayoritas responden pengunjung Apotek Kimia Farma 396 Tuminting kota Manado memiliki sikap terhadap penggunaan antibiotik yang tergolong cukup. Adapun faktor yang dapat menyebabkan sikap masyarakat masih tergolong cukup yaitu pengetahuan yang berhubungan sehingga dapat mempengaruhi sikap terhadap penggunaan antibiotik. Pengetahuan dengan sendirinya tidak cukup untuk mengubah perilaku, tetapi berperan penting dalam membentuk keyakinan dan sikap (Widayati et al., 2012).

\section{Pengaruh Tingkat Pengetahuan dan Sikap Terhadap Penggunaan Antibiotik \\ Uji normalitas digunakan untuk} mengetahui sebaran data terdistribusi normal atau tidak dengan menggunakan uji Kolmogrov-Smirnov. Berdasarkan hasil yang diperoleh, nilai asymptotic sig. (2-tailed) yang didapat yaitu sebesar 0,200 yang berarti bahwa nilai tersebut lebih besar dari nilai signifikan yaitu 0,05 yang berarti bahwa data tersebut terdistribusi normal. Jika data terdistribusi normal maka pengujian selanjutnya yaitu uji Paired Sample T-test. Berdasarkan hasil uji Paired Sample T-test yang diperoleh, nilai signifikan sebesar 0,000 yang berarti lebih kecil dari 0,05. Sebagaimana dasar pengambilan keputusan uji Paired T-test, maka dalam hipotesis $\mathrm{H}_{0}$ ditolak dan $\mathrm{H}_{1}$ diterima, yang berarti ada pengaruh antara tingkat pengetahuan dan sikap terhadap penggunaan antibiotik pada masyarakat pengunjung Apotek Kimia Farma 396 Tuminting kota Manado.

\section{KESIMPULAN}

Berdasarkan penelitian yang telah dilakukan, dapat disimpulkan :

1. Persentase tingkat pengetahuan antibiotik di masyarakat pengunjung Apotek Kimia Farma 396 Tuminting kota Manado masih kurang dengan persentase sebesar $69 \%$.

2. Persentase sikap masyarakat pengunjung Apotek Kimia Farma 396 Tuminting kota Manado terhadap penggunaan antibiotik tergolong cukup dengan persentase sebesar $45 \%$.

3. Terdapat pengaruh antara tingkat pengetahuan dan sikap terhadap penggunaan antibiotik masyarakat pengunjung Apotek Kimia Farma 396 Tuminting kota Manado.

\section{SARAN}

Disarankan bagi peneliti selanjutnya untuk melakukan penelitian sejenis pada wilayah kerja kota Manado yang berbeda sehingga dapat dilakukan pemetaan secara umum tentang pengaruh antara tingkat pengetahuan dan sikap masyarakat kota Manado terhadap penggunaan antibiotik.

\section{DAFTAR PUSTAKA}

Arikunto, S. 2006. Metode Penelitian Kuantitatif. Bumi Aksara, Jakarta.

Baltazar, F., Azevedo, M.M., Pinheiro, C., Yaphe, J. 2009. Portuguese Students Knowledge of Antibiotics: A Crosssectional Study of Secondary School and University Students in Braga. BMC Public Helath. 3(359): 1-6.

Carter, W. 2011. Disaster Manegement: A Disaster Manager's Handbook. ADB, Manila.

Departemen Kesehatan Republik Indonesia. 2009. Kategori Umur. Depatemen Kesehatan Republik Indonesia, Jakarta. 
Fitriani, N.L., Andriyani, S. 2015. Hubungan Antara Pengetahuan dan Sikap Anak Usia Sekolah Akhir (10-12 Tahun) Tentang Makanan Jajanan di SD Negeri II Tagog Apu Padalarang Kabupaten Bandung Barat Tahun 2015. Jurnal Pendidikan Keperawatan Indonesia. 1(1): 829-849.

Haryanto, A., Priambodo, A., Lestari, E.S. 2016. Kuantitas Penggunaan Antibiotik Pada Pasien Bedah Ortopedi RSUP Dr. Kariadi Semarang. Jurnal Kedokteran Dipenogoro. 5(3): 188-198.

Notoadmodjo. 2003. Pendidikan dan Penelitian Kesehatan. Penerbit Rineka Cipta, Jakarta.

Pangesti. 2012. Gambaran Tingkat Pengetahuan dan Aplikasi Kesiapsiagaan Bencana pada Mahasiswa Fakultas Ilmu Keperawatan Universitas Indonesia Tahun 2012 [skripsi]. Fakultas Ilmu Keperawatan, Universitas Indonesia, Jakarta.

Parumpu, F.A. 2016. Tingkat Pengetahuan dan Kepatuhan Masyarakat Dalam Penggunaan Amoxicillin Untuk Pengobatan Sendiri di Wilayah Kelurahan Lolu Selatan Kecamatan Palu Selatan. As-Syifaa. 8(2): 41-49.

Pratiwi, A. 2018. Hubungan Pengetahuan dan Sikap Terhadap Rasionalitas Perilaku Penggunaan Antibiotik Pada Masyarakat Sekampung Kabupaten Lampung Timur [skripsi]. Fakultas Kedokteran, Universitas Lampung, Bandar Lampung.

Pratiwi, R.I., Rustamadji, Widayati, A. 2013. Pengetahuan Mengenai Antibiotika di Kalangan Mahasiswa Ilmu-ilmu Kesehatan. Jurnal Forum Kesehatan. 2(10): 61-70.

Rahmawati. 2017. Pengetahuan dan Sikap Masyarakat Terhadap Antibiotik di Puskesmas Kota Jantho Kecamatan Kota Jantho Kabupaten Aceh Besar [skripsi]. Fakultas Farmasi, Universitas Sumatera Utara, Medan.
Santoso, S. 2016. Panduan Lengkap SPSS Versi 23. PT Elex Media Komputindo, Jakarta.

Tripathi, K.D. 2008. Antimicrobial Drugs: General Consideration. Essential of Medical Pharmacology. Jaypee Brothers Medical Publishers, New Delhi.

Widayati, A., Suryawati, S., Crespigny, C., Hiller, J.E. 2012. Knowledge and Beliefs About Antibiotics Among People in Yogyakarta City Indonesia: A Crosssectional Population-based Survey. Antimicrobial Resistance Infection Control. 1(1): 38-45. 